I have met with a perfectly similar deformity from fracture of fibula and injury to ankle-joint. You will experience no difficulty in distinguishing deformity of the ankle produced by disease or accident from similar changes in the form and position of the part, such as club-foot, and paralytic and spasmodic deformities. The history of the case, the nature of the stiffness, the dependence of the muscular contraction on causes primarily alfecting the structures composing the articulation, will determine your diagnosis.

In each of the forms of deformity of the ankle that $I$ have described, the rigidity of the articulation, whether resulting from adhesions within or without the capsular ligament, or from the consecutive muscular contraction, may be so considerable that scarcely any mobility of the bones entering into the composition of the articulation may be perceptible; thus, your opinion of the curability may depend on the detection of slight alternate tension and relaxation in the tendons of the contracted muscles whilst manipulating the limb.

The amount of lameness arising from these affections is often very considerable, and the inconvenieuce and pain experienced by the individual are usually greater than might be believed to exist. The circumstance which, in addition to the pain and discomfort attendant on locomotion with a stiff ankle-joint, occasiuns a ready application for relief is, the constant tendency, evinced in the severer forms, to increase the lameness and deformity consequent on the disturbance of the equilibrium of the muscles, and on the weight of the body being transmitted to the astragalus, whilst this boue is not situated horizontally beneath the axis of the limb, so as properly to communicate the weight, by means of the tarsal arch, to the ground. The portion of integument on which the greatest pressure in walking is exercised becomes excoriated or corered with painful corns, and sometimes severely inflamed.

Treatment.-The general treatment applicable to knee-ankylosis may be resorted to, with equal advantage, in slight cases in which the stiffness of ankle does not amount to apparent immobility. But if, from the duration of the affection, the intensity of contraction, or the failure of less active means, the case be judged irremediable without section of the more prominently contracted muscles, you may perform this operation; and it is fortunate that the treatment is liable to be attended with fewer inconveniences and interruptions than the similar affection of the knee-joint. Should contraction in the extended position of the foot exist subcutaneous section of the tendo-Achillis will, in most cases, sufficiently relax the articulation to permit its restoration; if the foot be rigidly fixed in the position of talipes equino valgus (elevation of the heel with eversion), the peronei may require division; if in that of $T$. equino varus (eleration of heel with inversion), the posterior tibial tendon, flexor longus pollicis, and plantar fascia should be included in the operation. In slighter modifications of each of these varieties, you should be satistied with seve. ring the tendo-Achillis, and trust to mechanical extension for the elongation of the re. maining contracted muscles and fasciæ.

I shall describe the apparatus applicable to these cases in a future lecture on some other deformities of an ankle.

\section{ON A}

\section{NEW METHOD OF TESTING ARSENIC,}

WITH REMARKS ON THE

\section{METHOD OF REINSCH.}

\section{To the Elitor of The Lancet.}

Sir,-While the name of M. Reingch, and the reputation of his beautiful process for detecting arsenic, are yet fresh in the memories of your readers, will you permit me to draw their attention, and your own, to a new method of testing for this metal, which I have been engaged for several months in experimenting on, and in endeavouring to render as free from fallacy as possible.

It had struck me, almost immediately after the publication of Reinsch's method, that if copper chips and wire possessed the remarkable property, as they do, of separating metallic arsenic from a solution of an oxide of the poison, it might so happen that arseniuretted hydrogen gas would also deposit its arsenic upon copper, if allowed to pass over it; and to my equal surprise and pleasure I found that, by the application of a very gentle heat, such proved to be actually the fact. I had previously altered and modified Marsh's instrument in such a manner as to cause it to give me a constant and uniform stream of gas; removing the brass stop-cock, which is objectionable on account of its being readily contaminated after one experiment with gas, and its being also very dificult, if not impossible, ever to clean thoroughly; and substituting a glass one in its stead, ground into a tube bent like a syphon, and having three hollow globes on its long leg, and three of equal size on the shorter. All this seems complicated in description, but it is simple enough in reality, and the additional balls have the effect of enlarging the gas-room of the apparatus without materially increasing its bulk, and consequently the supply of gas is continuous and not intermittent, as in the original apparatus; and, indeed, in the little instrument I use it often continues for hours, so as thoroughly to exhaust all the arsenic in the liquid under observation. I thought I had now a good opportunity of combining 
two or three different modes of testing in one apparatus; these are the arsenical stain, the reduction test, and the new mode which I will now very briefly describe.

Several pieces of clean, brightly polished copper wire of about an eighth of an inch in diameter, or some slips of thin copper ribbon (the latter are most convenient) are to be introduced into a tube of either German or English glass-it does not matter which, as no great heat is used in the process-which may be bent into an elbow at one end, and fitted with a perforated cork, if no better instrument be at hand, to a Florence flask at that end, the other being drawn out after the introduction of the copper into the tube to a capillary size. Some of the suspected matter, fluid or solid, with some pure zinc, pure sulphuric acid, and a little water (these latter must all be tested as to their freedom from arsenic previously), is then put into the flask so as to generate the arseniuretted hydrogen; this gas then passes over the surface of the copper wire, and may be burnt and tested in that way by the arsenical stain at the capillary extremity: a small spirit-lamp must, while the gas comes pouring over the copper, be held underneath it, so as to warm it for a few seconds, and almost instantly, if the arsenic be pretty abundant in the gas, the copper is seen to be frosted over with a coating of metallic arsenic, this deposit beginning at the end next the flask, and gradually extending until the whole surface is covered; the heat may be continued for a few minutes longer, and then withdrawn. If, however, the arsenic in the fluid being tested be small in quantity, then a minute or so may elapse before any indication of its presence is decisively given by the copper, but rarely longer. If it be requisite, and it is always expedient, to get as thick a crust as possible upon the copper, the heat must be continued for four or five minutes more; but if kept up after this, as no more copper surface remains exposed to the gas, and as probably the tube has become nearly red hot, then the arsenic begins to be deposited on the sides of the glass tube. It is rather singular that as long as any portion of the copper remains uncovered by this deposit, so long will the sides of the tube be perfectly clean and unstained, 'The copper may then be withdrawn, and it will be found to be coated over with a beautiful silvery crust of arsenic; this soon loses its lustre, and the wire appears as if it had been transformed into zinc or lead. It is to be noticed that every portion of its surface is covered with this crust, both that more directly exposed to the gas, and also that next the tubing. If antimony have been present instead of arsenic, the wire is blue, often iridescent, and is only coated on the parts directly exposed to the contact of the gas; a much more intense heat is requisite to get a deposit at all, and the sides of the tube are inva- riably stained owing to this increase in the temperature: In two words, antimony grequires more heat to decompose it than arsenic, when in combination with hydrogen gas, and this explains most of these pheno. mena, and, indeed, is of itself by no means an unimportant feature in the means of distinguishing the one from the other. The copper wire or ribbon is now to be cut into small pieces a sixth or a fourth of an inch in length, put into a tube drawn out at one end fine so as to prevent their slipping through, and heated gently over a small flame until the chips are nearly of a cherry-red heat.

1. If the deposit be arsenic, long before all the crust is oxidised off, evidence, beautifully decisive and clear, is obtained of its presence in the deposition of the brilliant, glis. tening, transparent little crystals of arsenious acid, in a ring, presenting a sharplydefined margin towards the copper chips, and shading gradually off towards the open larger end of the tube. A Stanhope lens is suficient to complete the proof; the ring, which is distinctly - if I may use the word, unmistakeably-crystalline to the unassisted eye, is found on examination to consist of, octahedral crystals, the triangular facets being presented to the eye; sometimes they appear tetrahedral, probably from the octa. hedron lying on its edge, and presenting the faces of the two opposed triangles towards the observer. I feel quite certain that any one who had but once seen them could never again either forget or mistake any thing else for them. After their shape has been clearly made out, the farther proofs of their nature may be ob. tained, as Dr. A. T. Thomson and Dr. Christison have shown, by dissolving out the arsenious acid with a little water, containing a few drops of nitric acid or ammonia, dividing the solution into three parts, sending a little stream of sulphuretted hydrogen gas through one, and adding the solution of the ammonio-nitrate of silver and of the am. monio-sulphate of copper to the two others; and now the orange, the lemon-yellow, and the grass-green precipitates, decide the matter.

2. Suppose, however, the deposit on the copper is antimony, it must be treated in just the same manner, and it will be noticed that the heat requisite for obtaining any oxide is much greater than that in the arsenical case; that, instead of the crystalline ring, a film of a white, amorphous, uncrystallised powder is obtained, sometimes forming an indistinct ring, never having so sharp a margin as the arsenical, and sometimes left like a delicate white dust along the length of the tube : altogether, the result of the process is as remarkably indefinite and uncertain in this case as in the former it is definite and decisive.

You will, of course perceive Sir, that this oxidation test is that which was proposed originally, I believe, by the late Dr. Turner, 
so that all which is mine in the process is the first part of it-the method of getting the deposit. The whole matter appears infinitely more complex and difficult on paper than it is in operation; and, indeed, the chief beauty of the whole consists in its simplicity, its certainty, and the facility with which the most inexpert toxicologist may obtain his evidence. I at once admit, and, indeed, those who have troubled themselves so far as to wade to this depth in this account will almost anticipate my avowal, that inasmuch as Reinsch's test has been fairly proved to be somewhat-although, I think, not as much as is generally stated-more delicate than Marsh's, so it of necessity follows that it must be more delicate than mine, as both my test and Marsh's depend for their essence upon the generation of arseniuretted hydrogen gas.

The reasons which, perhaps, I may urge why this metbod may be adopted with as much confidence, if not more, than that of Reinsch, are the following:-The arsenical deposit is more decisive in its aspect, and more readily and at once distinguished from that of antimony by its silvery lustre, and by the blue, sometimes powdery aspect of the latter; and the very process of getting the deposit gives some help to the tester to diagnose his poison, from the slight heat requisite to obtain it from arsenic, and the greater from antimony, the tube being clean with arsenic, stained with antimony, and the deposit being most frequently, if not always, on every portion of the surface with arsenic, and chiefly on the exposed surfaces only, with antimony. For all practical purposes it is as delicate, and, I believe, is not affected, at any rate to any confusing degree, by the other metals, tin, bismuth, \&c., which affect M. Reinsch's : on this, however, I do not lay much stress, as it requires more investigation than $I$ have as yet been able to give to it.

As to the question of its delicacy, I have little farther to state than this, that it seems to me that this point is overstrained. I have examined a great many reports of cases of poisoning by arsenic, and from all $I$ can collect from them 1 cannot but infer that it seems,improbable, at the least, that the poison should have been the cause of death, if it be not detectable from examination of either the vomited matters, the lining of the alimentary canal, the blood, and particularly the urine, if any can be obtained, by the generation of the arseniuretted hydrogen. So strong seems the affinity of arsenic to hydrogen to me, that the quantity must be almost infinitesimal if it will not show itself, and, if it $d \omega$, then my test will find it out; so that, unless a man be poisoned by some homoeopathic murderer, we shall have evidence enough to prove the existence of the arsenic by this method alone. I have particularised the urine, as I do not find in the cases I have examined any mention of $i t s$ analysis; and Orfila has shown that the kidneys do their utmost when arsenic is in the system to get it out again, unless its nar. cotic effects shall have at all paralysed them : in some future case it might be worth while aitending to this point.

I may mention, before proceeding further, that if the quantity of arsenic be very minute, it is advisable to keep up a constant gentle heat, confining portion after portion of the gas over the wire by closing the end of the tube, until all its arsenic has been deposited.

Thus far, perhaps, it might have been foreseen that arsenic would be deposited upon copper when heat was applied, as we find it deposited on the sides of the tube under apparently similar circumstances; but it is to be observed, first, that the heat requisite for the decomposition of the gas must in the latter case be carried to redness, while the copper requires much less intensity of degree; and, secondly, that the sides of the tube are left clean when copper is heated in the gas, facts which seem to prove that the arsenic has an affinity in the copper not depending on the chemical alteration produced in the gas by the heat alone. Even so far there is nothing either very unusual or very extraordinary; but I now come to a fact which does seem both new and singular; it is this. I have found that when copper wire or ribbon is exposed per se unheated, and unaided in any other way, to a stream of arseniuretted hydrogen, it possesses the property of decomposing it, and causing the arsenic to be left as a metallic crust just similar to that obtained in the former experiments upon its surface. This decomposition is rather slow; perhaps it may take twenty minutes or half an hour before all the surface is covered, but it is not the less certain.Let it be now tested by oxidation; cut the wire into small chips, and very carefully dry it, so as to drive off some moisture on its surface, as this, if not driven away, rises with the crystals of arsenious acid, and is apt to dissolve off their angles, making them look like truncated cylinders. Heat them now as before, and as before will be seen that decisive and indubitable proof of the nature of the coating, the little crystals of arsenious acid, in a delicate zone on the tube.

This is not all, however. This deposit of arsenic will not take place (as far as I have been able to make out), unless the surface of the copper be in a particular condition; and when 1 first distinctly proved this, I was congratulating myself on my good fortune in being able to add another to the list of katalytic decompositions. However, my selfgratulation died away upon a little more reflection, and the apparently reasonable explanation of this singular circumstance will be given immediately. The particular con- 
dition of the surface to which I have alluded is rather remarkable. If the copper be perfectly bright and clean, I have never succeeded in getting any deposit on it when exposed without heat to the gas; but if, however, the copper be heated in a fire until it is dull red, and then suddenly plunged into cold water, althourh this last is not essential but simply convenient for purity's sake, then it will recompose the gas. If this has been properly managed, and it requires very little attention to do so, the surface of the copper should be of a maroon or reddish brown calour; this seems to arise from superticial oxidation of the metal taking place whilst it is passed from the fire to the water. It must be observed that if the copper be heated to bright redness and then suddenly cooled, this oxide falls off, or the metal is technically said to "scale;" and then it again loses its decomposing powcr.
All these circumstances go to prove that it is necessary to have a surface not of copper alone, but of its oxide; and I have found in a vast number of experiments that this is really the case; and I have by me now many specimens where the copper has partly scaled and part not; and on the parts where the scale has not fallen off arsenic is depo. sited, while on the clean surface there is not a trace of it. This would seem at once to point to its own explanation, and that which seems most probable and rational to me is this: we have an oxide of copper, over which a gas containing arsenic and hydro. gen is passed; the hydrogen I suppose to combine with the oxygen of the oxide, and to form water, while the arsenic is deposited on the copper in its metallic state. This may appear clearer by the following dia. gram :-

Red sub-oxide of Copper

$$
\begin{gathered}
\mathrm{Cu}_{2}+\mathrm{O}
\end{gathered}\left\{\begin{array}{r}
\mathrm{Cu}_{2} \\
\mathrm{O}
\end{array}\right.
$$

Arsenic deposited on Copper.

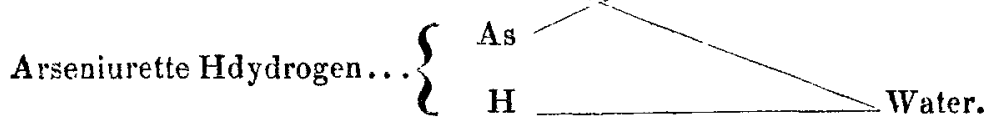

In support of this I may add that I have over hidden mines, and does not find out his noticed the deposition of minute globules or po:nts of water on the surface of the copper after it had been exposed to the gas, altbough I had taken means to dry the gas previously.

I have not heard of any explanation of the method in which arsenic is deposited in M. Reinsch's test; may I venture to offer the following rationale:-

We have hydrochloric acid and arsenious acid in solution in water, with slips of metallic copper; this solution, heated to $212^{\circ}$, a chloride of copper is formed, and the hydrogen resulting frum the decomposition may, I think, form arseniuretted bydrogen, from decomposition of the arsenious acid, the oxygen of which may unite with the proportion of hydrogen and form water, while the arsenic is deposited as a metallic coating upon the chloride of copper, and the lydro. gen again liberated to decompose a fresh portion of arseuious acid. If this explanation, complicated, as it appears, be correct, then, aftel' all, Reinsch's test is but a moditication of Marsh's; but I fear some more learned chemist than myself will unpick this theoly of mine. I hope, however, some better one may be found in its stead. Surfuce appears to have no effect on arsenious acid in solution; that is to say, no arsenic is depo. sited on either a bright or an oxidated surface; and, indeed, if my explanation be correct, why should it, so long as we withhold the materials for the supply of the hy. drogen, which appears the sine qud non of the experiment.

I must, however, stop theorising further, Marsh," as the French call him, Orfila, at as a young chemist in so doing always walks Paris, who, while he smiled at the compli-

Do not, however, let me be misunderstood about this last process of mine. I do not urge $i t$ as a test for arsenic; it is too slow in operation, and is liable to be influenced by many trifling circumstances which might in. terfere with its indications. I have merely alluded to it in this paper as I believe it to be a novelty in chemistry, and one that at first sight appears rather startling. I wish I could explain away all apparently katalytic actions as readily as $I$ hope this bas been explained. It may be that some equally simple causes influence them could they but be found out. I first found that it required the surface to be modified by accidentally putting into the gas a piece of wire which I had heated, and then cooled in water just to cleanse it from some impurity. I hope there may not have crept into this acconnt any very serious mistake, as I have made some hundreds of experiments on the subject, fearing my own manipulation for sone time, until at last I could not but be convinced that the facts are really those which I have occupied so much - too much, indeed-of your Journal in detailing. I $\sin$. cerely trust, however, some more expert and experienced toxicologist than myself will take up the matter, if it be worth the trouble, and then decide the accuracy or the falsehood of my experiments.

Before closing, I may add that I had the pleasure of showing the results of my first process to that "Prince de l'Appareil du 
cated aspect of a sketch of my modification of Marsh's instrument, seemed pleased with the results of the test. A pologising to you, Sir, and to your readers for so long encroaching on your time and patience and on theirs, I remain, Sir, your reader,

Robert Ellis.

University College, Oct. 25, 1843.

RUPTURE OF THE HEART, AND SUDDEN DEATH.

To the Editor of The LanceT.

Sir,-I send you the particulars of a case of rupture of the heart, which, I think, will be worth communicating, as examples of it occur rarely, and may then become the subject of medico-legal inquiry, as in this instance :-Mrs. Keele, aged 53 years, the wife of a farmer's labourer, was taken ill suddenly on the morning of the 20th ult., and died in the course of half an hour. On my arrival the body was still warm, but afforded no indication of the cause of death, I therefore obtained an order from the coroner for a post-mortem examination. In answer to my inquiries the husband of the deceased stated that she had been in very good health, and only the day before had walked five miles with a burthen, but she had complained frequently of a bronchocele, which embarrassed her breathing at times, and to which he attributed her death. In December, 1842, she was ill with fever, and had an inflammation of the chest (but no decided information can be obtained on this point).

At half-past three, a.m., of the abovementioned day she was awakened by severe cough and difficulty of breathing. After making signs of great suffering about the throat she "reared up" suddenly, and fell forward on the bed; when he obtained assistance she was quite dead. Two hours after death I found that the body had been laid ont; it was that of a person of middle stature and spare conformation; the limbs were relaxed, and the face and general surface very pallid. There was a goîtrous tumour, which was not tense, nor of a size to justify the inference of death from that cause.

Autopsy, Thirty Hours after Death.-The body was now quite rigid and much congested in the depending parts; there was no cedema of the lower extremities. On the sternum being raised the lungs collapsed moderately; the pericardium was quite flaccid, and not at all encumbered with fat; the heart was found occupying its normal position, but obviously enlarged and much charged with fat. The right ventricle was collapsed, and on the middle of its anterior surface, close to the septum, I observed a depression which proved to be a perforation into its cavity, large enough to adnit a goose quill, and showing one of the deshy columns through it. About an ounce and a half of fluid blood was effused into the pericardium; the inner surface of this nembrane was marked by two small white patches of $1 \mathrm{ymph}$ anteriorly, but was otherwise healthy. The heart was removed, the usual quantity of dark blood flowing from the divided vessels : its weight was eleven ounces (avoirdupois). There was a thick deposit of jellow fat under the serous covering, most abundant at the base and in the course of the coronary arteries; also on the anterior surface. The superficial vessels were much injected. On the cavities being laid open, the muscular tissue appeared somewhat pale and softened, its fibres being intermixed with fat. The right rentricle rather dilated, and its walls much thinned, so that near the point of rupture their thickness did not exceed half a line, and here the accumulation of fat was greatest. The opening was of irregular shape, with a torn edge and its greatest diameter transverse, and was situated two lines from the septum. The endocardium and valves were not at all diseased.

The left ventricle, which contained no coagnala, was ten lines thick in the middle of its wall; the lining membrane of the aorta in its commencement was dyed of a bright red colour, and marked with numerous white spots. The aortic valves presented the same appearances, and there were several patches of redness on the musculi papillaris.

The lungs were everywhere adherent to the costal pleura inferiorly; the surface of a deep red, and near the anterior margios studded with emphysematous vesicles. The tissue of the lung was highly congested, but crepitated well on pressure.

The bronchi contained much mucus, and their mucous membrane was injected, as well as that of the trachea. The bronchial glands were enlarged, and many of them filled with calcareous matter.

The bronchocele consisted chiefly of enlargement of the central portion of the thyroid body, and was the size of an orange. A section of it exhibited the usual cellular structure, with a fibrinous centre. The other cavities were not examined.

The only comment that $I$ have to make on the case is that a very small quantity of blood was effused from a considerable breach in the ventricle, whence I conclude that death must have been instantaneons from the heart's action being suspended by pressure of the sudden effusion. I remain, Sir, your obedieut servaut,

Guildford, Oct. 30, 1843.

$$
\text { Henry T. Taylor. }
$$

In February and March, 1843, as many as 11,311 individuals were received into the various hospital in Vienna and its neighbourhood, of whom 5650 were afterwards discharged cured, and 670 died before April arrived. 